\title{
READING AND CHILDREN WITH DEVELOPMENTAL LANGUAGE DISORDER: A CASE OF GREEK STUDENTS
}

\author{
Georgia Andreou', Vasiliki Aslanoglou, Vasiliki Lymperopoulou ${ }^{3 \star}$ \\ ${ }^{1}$ Professor, University of Thessaly, GREECE, andreou@sed.uth.gr \\ ${ }^{2} \mathrm{PhD}$ student, University of Thessaly, GREECE, vaaslano@uth.gr \\ ${ }^{3} \mathrm{PhD}$ student, University of Thessaly, GREECE, lymperopoulouv@gmail.com \\ ${ }^{*}$ Corresponding author
}

\begin{abstract}
Fluent reading is essential for the comprehension of a text, as well as for the pleasure that a person feels while reading. However, it is a complex process that requires linguistic, cognitive and perceptual abilities. Children with a diagnosis of Developmental Language Disorder exhibit deficits in language development that have an impact on their reading skills. The present study investigated the reading performance of children with Developmental Language Disorder (DLD) and compared it to that of a group of typically developing (TD) children matched for gender and chronological age. The study took part in Greece and the participants of the study were 62 children, 31 with DLD ( $M=91.84$ months) and 31 TD ( $M=92.55$ months). In the first task the participants were asked to read aloud a set of fifty pseudowords in a minute and in the second task they were asked to read forty-two sentences and complete them with the word missing, choosing from a set of words within forty minutes (only one of the given words was the right one). The first task assessed the total number of pseudowords the children read (correctly or not) and, also, the total number of the pseudowords they read correctly in one minute. The second task assessed the total number of the correctly completed sentences. The findings of the study showed that the outputs of the DLD group were poorer in all measurements compared to those of their TD peers. Specifically, in the first task the DLD group tended to read less pseudowords in total and less pseudowords correctly than their TD peers. Moreover, in the second task the DLD group completed correctly less sentences than the TD group of participants. All the above indicate the difficulties the DLD group faces in reading tasks and implicate the need for further research.
\end{abstract}

Keywords: Reading, Developmental Language Disorder, DLD

\section{INTRODUCTION}

\subsection{Reading Acquisition}

Reading is a crucial skill for school and academic development and for the daily life of individuals, as reading is the basis of formal education (American Federation of Teachers, 2008). Reading requires a range of skills from the learner, such as visual discrimination and visual memory. In addition, auditory discrimination, auditory memory, auditory sequencing, and auditory blending are considered as essential abilities for reading acquisition (Kamei-Hannan \& Ansari Ricci, 2015). 
Reading acquisition relies on mechanisms that should be assimilated and on procedures that should be followed (NRP, 2000a). More specifically, phonemic awareness is essential for reading acquisition, as it refers to the ability of an individual to split a word into phonemes or to combine phonemes in order to create a word. Moreover, the acquisition of phonemic awareness is crucial for the alphabetic principle and phonology (Ehri, 2005). The alphabetic principle concerns the ability to understand that the letters / symbols we observe, for example in a newspaper clipping, are related to the sounds used in oral speech and are also important for reading. Moreover, reading fluency enhances reading as it enables readers to understand the meanings of the text, while the weak readers expend their energy on reading each word correctly, and as a result they forget the content of what they have read. Vocabulary and comprehension (Harris \& Hodges, 1995) are, also considered to be essential skills for mastering reading. The knowledge of a wide range of words enables readers to better understand a text, while reading comprehension concerns the ability to understand the written information and to use it for a specific purpose (Harris \& Hodges, 1995). Moreover, spoken language and memory are important factors for reading acquisition, while prior knowledge helps the readers to connect the information they read with the staff they already know. Finally, attention and concentration, motivation, interest and receptive skills have a prominent role in learning to read (Gagne, Yekovich, \& Yekovich, 1993).

A competent reader is able to read at a proper pace, to recognize words automatically and to proceed to oral reading using the appropriate voice colouring and rhythm. On the other hand, incompetent readers read slowly, spend a lot of time to decode unknown words and sometimes they face difficulties in understanding what they read.

\section{According to Chall (1983) six stages of reading acquisition are observed:}

Stage Zero: The Pre-reading stage extends from a person's birth to the age of six years. In this stage, children reach the first grade of Primary School and have acquired about 6,000 words in their receptive and expressive vocabulary. At this stage some children can write their name and recognize some letters or even whole words. In addition, they sometimes pretend to read (for example, a story often read to them by their parents or a recipe, etc.).

Stage 1: The Initial reading or decoding is the second stage and concerns children who attend the $1^{\text {st }}$ to the $2^{\text {nd }}$ grade of Primary School. During this stage children use the alphabetic principle in order to read.

Stage 2: During this stage that refers to children who attend the $2^{\text {nd }}$ to the $3^{\text {rd }}$ grade of Primary School, students develop and consolidate their expression skills, while they automatically recognize many unfamiliar words and they are able to read them correctly.

Stage 3: This stage concerns the grades $4^{\text {th }}$ to $8^{\text {th }}$, while children acquire new knowledge through reading. Texts may contain words unknown to children.

Stage 4: During the fifth stage that refers to students who attend the grades $9^{\text {th }}$ to $12^{\text {th }}$, they are able to read texts that present multiple opinions and perspectives. The vocabulary of the texts becomes complex, as it concerns specific areas. The readers are asked to critically approach the texts they read.

Stage 5: The final stage concerns adults and is correlated with the university and in general their later life. In this stage the readers proceed to read books, articles or material that will offer them the information they are looking for.

Furthermore, National Early Literacy Panel (2008) has recorded four stages concerning reading acquisition.

Emergent Reading is the first stage and concerns pre-school children. During this stage, children are able to understand that the letters / symbols they see on a page of a children's book or on product packaging produce specific sounds and they usually develop important skills, such as knowledge of letters and sounds, phonological awareness, recognition of certain words they see in a specific context (National Early Literacy Panel, 2008).

In the next stage that is referred as Beginning Reading, children develop reading skills and they are able to read 50-100 words per minute. In this stage, they read in order to learn and they do not learn to read.

During the third stage (Advanced Reading), reading is utilized by the students as a tool to gain new knowledge.

Finally, in Academic Reading, individuals have developed specialized vocabulary that is even related to specific scientific areas (eg economics, physics, philosophy, mathematics, etc.). 


\subsection{Developmental Language Disorder}

Developmental Language Disorder (DLD) is a neurodevelopmental language disorder (Sengottuvel \& Rao, 2015) which includes a broad range of language difficulties, while simultaneously, the language profile of individuals with DLD presents considerable heterogeneity (Ryder, Leinonen, \& Schulz, 2008). The diagnosis of DLD is usually occurred at pre-school age and includes difficulties in producing and/or understanding language that affect their daily life and remain in school age and even in adulthood.

The term "Specific Language Impairment" (SLI) was used in the past to describe individuals who did not have typical language development but whose development in other domains was typical. However, this terminology was based on exclusion criteria and therefore it was replaced by the term DLD, which takes into consideration inclusion criteria (Bishop, Snowling, Thompson, Greenhalgh, \& the CATALISE Consortium, 2016; Leonard, 2014; Stavrakaki, 2019).

The genetic etiology of DLD is complex and, therefore it cannot be justified by the mutation of a gene (TagerFlusber, 1999). DLD is not attributed to biological factors (Bishop et al., 2016 and it is not correlated with any obvious etiology, such as hearing loss, low non-verbal intelligence or any neurological disorder (Haebig, Sterling, \& Hoover, 2016; Montgomery, Gillam, \& Evans, 2016). Moreover, it is possible for DLD to be comorbid with others neurodevelopmental disorder and therefore neurological or environmental factors, such as attention deficit, hyperactivity or behavioral problems should not be considered as exclusion criteria for the diagnosis of DLD (Bishop et al., 2016).

The difficulties individuals with DLD face concern nonword repetition (Baddeley, Gathercole, \& Papagno, 1998; Bishop, North, \& Donlan, 1996; Lalioti, Stavrakaki, Manouilidou, \& Talli, 2016; Larkin, Williams, \& Blaggan, 2013; Mengisidou, Marshall, \& Stavrakaki, 2020), phonological awareness, oral speech production (Catts \& Kahmi, 1986), reading and verbal short-term memory (Girbau \& Schwartz, 2007; Hill, 2001). Deficits are also observed in morphology (Abel, Rice, \& Bontempo, 2015; Rice, Wexler, \& Cleave, 1995; van der Lely \& Ullman, 2001), and especially in the use of passive voice (van der Lely, 1996) and in question clauses (Stavrakaki, 2019; van der Lely \& Battell 2003). In Greek language, children with DLD exhibit difficulties in acquiring the definite article and the weak types of personal pronoun (Tsimpli \& Stavrakaki, 1999). Moreover, deficits in reading comprehension and in understanding complex and large sentences are observed (van der Lely \& Battell, 2003; Talli, Sprenger-Charolles, \& Stavrakaki, 2016), while children with DLD produce short sentences and face difficulties in narrative (Andreou \& Lemoni, 2020). Semantic and pragmatic levels of language are also defective domains (Leonard, 2014).

The difficulties children with Developmental Language Disorder face in reading are identified by a number of studies and are linked to various proposed theories. Some of them link the difficulty faced by individuals in the reading process with deficiencies related to the necessary reading skills (Francis, Shaywitz, Stuebing, Shaywitz, \& Fletcher, 1996). Some theories argue (Stanovic, Nathan, \& Zolman, 1988) that the slower development of children with DLD compared to that of children with typical development at the beginning of reading learning is due to underlying delays in cognitive skills which, over time, will be acquired. Other researchers ('Matthew-effect' model) (Stanovich, 1986) emphasize that children who initially have low reading performance, are not exposed to reading material as often as their TD peers and as a result they have low performance. The first theory is supported by an amount of research related to Developmental Language Disorder (Bishop \& Snowling, 2004; Botting, Simkin, \& Conti-Ramsden, 2006; St. Clair, Durkin, Conti-Ramsden, \& Pickles, 2010).

\section{STUDY AIM AND HYPOTHESIS}

The aim of the present study is to investigate whether the group of children with Developmental Language Disorder (DLD) performs worse compared to their typically developing (TD) peers of a corresponding chronological age while reading. The hypothesis of the study is that the DLD group will perform worse than the TD group in both reading tasks they are asked to participate.

\section{METHODOLOGY}

\subsection{Participants}

Our sample consisted of 31 children with DLD ( 7 girls and 24 boys) and 31 TD children ( 7 girls and 24 boys) of a corresponding chronological age. The mean age of DLD participants was 91.84 months and the mean age of TD participants was 92.55 months. Children with DLD were recruited from speech therapists' offices, they attended Greek public schools and they had an official diagnosis for language difficulties. Moreover, they showed language disorders in the past years, they were monolingual students and at the time of testing 
they didn't face any hearing loss or visual impairment or any known neurological disorder. In addition, they faced problems while reading and writing and they all had normal nonverbal IQ ability.

\subsection{Materials}

Both groups were asked to participate in two reading tasks. The first task included a set of fifty pseudowords and the second task consisted of forty-two sentences each one including a missing word (Tafa, 1995).

\subsection{Procedure}

For the purposes of the study all participants initially had the written consent of their parents. The children with DLD were assessed individually in a quiet room of their speech therapists' offices while children of typical development were tested in small groups in a quiet classroom of their school. In the first task which consisted of a set of fifty pseudowords each participant was asked to read the pseudowords aloud in a minute. In the second task which consisted of forty-two sentences they were asked to read them silently and complete each sentence with the missing word choosing from a set of given words within forty minutes. Only one of the given words was the right one. No extra time was given in both tasks by the researcher even if the participants didn't manage to read all the pseudowords in the first task or if they didn't handle to complete all the sentences in the second task. Also, the researcher didn't give any further explanation during the time of testing.

The first task assessed the total number of pseudowords children read (correctly or not) and, also, the total number of pseudowords they read correctly in one minute. The second task assessed the total number of the correctly completed sentences.

\subsection{Statistical Analysis and Results}

The statistical analyses of the data were performed with the Statistical Package for Social Sciences (SPSS) software and more specifically via t-Test. As presented in table 1 and in figure 1 the results of both tasks showed that there was a statistically significant difference between the DLD group and the TD group in all measurements. More specifically, a) in the total number of correctly read pseudowords in $1^{\prime}$ minute (DLD M= 27.19, SD=6.96; TD $M=37.61, S D: 8), b$ ) in the total number of correctly or not read pseudowords in $1^{\prime}$ minute (DLD $M=30.71, S D=7.69$; TD $M=40.81, S D: 8.44$ ), c) in the Reading Ability Detection Test (DLD $M=$ 93.68, $S D=15.37$; TD $M=105.06$, SD: 13.97).

Table 1

Results of the DLD and TD group in reading tasks

\begin{tabular}{|l|c|c|c|c|c|}
\hline & \multicolumn{2}{|c|}{ DLD (N=31) } & \multicolumn{2}{c|}{ TD (N=31) } & \\
\hline & M & SD & M & SD & t - Test \\
\hline $\begin{array}{l}\text { Total number of correctly read pseudowords in } \\
1^{\prime} \text { minute }\end{array}$ & 27.19 & 6.96 & 37.61 & 8 & $-5.47^{* * *}$ \\
\hline $\begin{array}{l}\text { Total number of read pseudowords in 1' } \\
\text { minute (correctly or not) }\end{array}$ & 30,71 & 7,69 & 40,81 & 8,44 & $-4.92^{* * *}$ \\
\hline Reading Ability Detection Test & 93.68 & 15.37 & 105.06 & 13.97 & $-3.05^{* *}$ \\
\hline
\end{tabular}

Note: DLD = Developmental Language Disorder, TD=Typical Development

${ }^{* *} p<.05,{ }^{* * *}=p<.005$

\section{DISCUSSION}

The research hypothesis of this study was that children with Developmental Language Disorder are expected to exhibit lower performance in reading tasks in comparison to that of children of typical development of a corresponding chronological age and gender.

The tasks used concern both the ability to decode (Read Pseudowords) and the ability to understand (Test of Detection of Reading Ability). The results confirmed our research hypothesis, as the performance of children with Developmental Language Disorder was lower compared to their TD peers in both reading 
tasks. More specifically, regarding the first task (Reading Pseudowords), a double measurement was occurred and it was observed that children with Developmental Language Disorder read correctly less pseudowords and they read fewer pseudowords (correctly or not) in total in 1 minute in comparison to their TD peers. Accordingly, in the second task children with DLD performed weaker than their TD peers. These findings are in line with the relevant literature that refers to the performance of children with Developmental Language Disorder in reading tasks that examine either decoding or understanding the texts. Our results are similar to the results of the research of Williams, Larkin, \& Blaggan (2013) on the written speech of children with Developmental Language Disorder. In their research, during the reading task, participants were asked to read a series of words from a card presented to them. The words were initially easy and then the degree of difficulty escalated. Participants read the words aloud and received a grade for each word they read correctly. According to the results, a statistically significant difference between DLD group and the two control groups (age-matched and language-matched) in their performance in this reading task was observed. More specifically, children diagnosed with Developmental Language Disorder had significantly lower performance than their TD peers. Moreover, our conclusions are in line with the research of Mackie \& Dockrell (2004), in which the reading ability of the participants was assessed using the test WORD (Rust et al., 1993). In addition, Dockrell, Lindsay, Connelly, \& Mackie (2007) investigated the reading ability of 64 children with Developmental Language Disorder at two time points (at 8 and at 10 years) using word reading tasks and content comprehension tasks through reading and they found that children with DLD have a difficulty in the reading process. Also, the findings of this study regarding the reading ability of children with Developmental Language Disorder agree with those of the research of Rodriguez, Santana, Hernández, \& Bermudez (2016). In this research, participants performed significantly lower on all reading-related tasks (eg reading individual words and pseudowords, comprehension of sentences and texts, etc.) than the TD group. Furthermore, the results of the present study are consistent with the research of Isoaho, Kauppila, \& Launonen (2015) in Finnish (Finnish orthographic system is characterized by a high degree of transparency). The researchers examined the reading ability of Finnish students at the end of the 1st, 2nd and 3rd grade (ages 7 to 10). Even at the age of ten only $20 \%$ of children with Developmental Language Disorder achieved the average performance. Regarding the comprehension, the performance was slightly higher $(32.5 \%$ of children with Developmental Language Disorder were able to achieve the average performance). Finally, the results of this study are in accordance with those of Botting et al. (2006), who examined word reading and text comprehension of children with DLD at the ages of 7 and 11 years and found that the participants presented difficulties in both time points of the assessment.

The multiple difficulties children with a diagnosis of Developmental Language Disorder face in reading are associated with deficits they present in language development. Specifically, Bishop \& Snowling (2004) report on phonological deficits and oral speech deficits that are common to this population. The above researchers claim that phonological deficits are a crucial risk factor for difficulties in reading decoding, while deficits in spoken language are factors that are likely to affect reading comprehension. Difficulties in decoding words / texts etc. are associated with phonological deficits (Catts, 1993; Wagner \& Torgesen, 1987), while difficulties related to comprehension are associated with difficulties in writing and processing speech (Larrivee \& Catts, 1999; Stothard \& Hulme, 1992). Children with Developmental Language Disorder are characterized by deficits in phonological awareness that are associated with the ability to decode words in the early stages of reading (Cunningham \& Stanovich, 1997; Stanovich 1988). Passenger, Stuart, \& Terrell (2000) recorded the fact that phonological awareness contributes significantly to the acquisition of early reading and reading of words. In addition, the researchers highlighted the importance of phonological memory for the acquisition of reading, which plays an important role in the development of strategies that enhance the reading comprehension. Deficits in morphological awareness of children with DLD are also likely to be related to their difficulties in reading (Carlisle, 2000; Singson, Mahony, \& Mann, 2000).

It should be noted that it is extremely important to take into account the language in which each research on the reading ability of individuals is conducted. In particular, in languages with transparent spelling systems (such as German, Italian, Spanish) children are able to perform better and acquire reading earlier than their peers by non-transparent spelling systems (such as French or English). More specifically, Seymour, Aro, \& Erskine (2003) examined the reading skills of participants from twelve European countries and they found that children whose language had a transparent spelling system acquired a higher percentage of reading skills even at the end of the first grade of school as compared to children whose language had a nontransparent spelling system and so the second group of children had a delay in acquiring reading in a similar degree. 


\section{REFERENCE LIST}

Abel, A.D., Rice, M.L., \& Bontempo, D.E. (2015). Effects of verb familiarity on finiteness marking in children with specific language impairment. Journal of Speech, Language, and Hearing Research, 58, 360372. https://doi.org/10.1044/2015_JSLHR-L-14-0003

American Federation of Teachers (2008). Improved early reading instruction and intervention. In C. KameiHannan \& L. Ansari Ricci (2015). Reading connections. Strategies for teaching students with visual impairments. New York: AFB Press.

Andreou, G., \& Lemoni, G. (2020). Narrative Skills of Monolingual and Bilingual Pre-School and Primary School Children with Developmental Language Disorder (DLD): A Systematic Review. Open Journal of Modern Linguistics, 10, 429-458. 10.4236/ojml.2020.105026

Baddeley, A., Gathercole, S., \& Papagno, C. (1998). The phonological loop as a language learning device. Psychological Review, 105, 158-173. https://doi.org/10.1037/0033-295X.105.1.158

Bishop, D.V.M., North, T., \& Donlan, C. (1996). Nonword repetition as a behavioural marker for inherited language impairment: evidence from a twin study. Journal of Child Psychology and Psychiatry, 37, 391-403. https://doi.org/10.1111/j.1469-7610.1996.tb01420.x

Bishop, D.V.M., \& Snowling, M.L. (2004). Developmental dyslexia and specific language impairment: Same or different? Psychological Bulletin, 130, 858-886. https://doi.org/10.1037/0033-2909.130.6.858

Bishop, D.V.M., Snowling, M.J., Thompson, P.A., Greenhalgh, T., \& the CATALISE Consortium (2016). CATALISE: A multinational and multidisciplinary Delphi consensus study. Identifying language impairments in children. PLOS one, 11 (7). https://doi.org/10.1371/journal.pone.0158753

Botting, N., Simkin, Z., \& Conti-Ramsden, G. (2006). Associated reading skills in children with a history of Specific Language Impairment (SLI). Reading and Writing, 19, 77-98. https://doi.org/10.1007/s11145005-4322-4

Carlisle, F.J. (2000). Awareness of the structure and meaning of morphologically complex words: impact on reading. Reading and Writing, 12, 169-190.

Catts, H.W., \& Kahmi, A.G. (1986). The linguistic basis of reading disorders: Implications for the speechlanguage pathologist. Language, Speech, and Hearing Services in Schools, 17, 329-341. https://doi.org/10.1044/0161-1461.1704.329

Catts, H. (1993). The relationship between speech-language impairments and reading disabilities. Journal of Speech and Hearing Research, 36, 948-958. https://doi.org/10.1044/jshr.3605.948

Chall, J.S. (1983). Stages of reading development. McGraw-Hill.

Cunningham, A., \& Stanovich, K. (1997). Early reading acquisition and its relation to reading ability 10 years later. Developmental Psychology, 33, 934-945. https://doi.org/10.1037/0012-1649.33.6.934

Dockrell, J.E., Lindsay, G., Connelly, V., \& Mackie, C. (2007). Constraints in the production of written text in children with Specific Language Impairment. Exceptional Children, 73(2), 147-164. https://doi.org/10.1177/001440290707300202

Ehri, L.C. (2005). Learning to read words: Theory, findings and issues. Scientific Studies of Reading, 9(2), 167-188. https://doi.org/10.1207/s1532799xssr0902_4

Francis, D, Shaywitz, S, Stuebing, K, Shaywitz B, \& Fletcher, J. (1996) Developmental lag versus deficit models of reading disability: A longitudinal, individual growth curves analysis. Journal of Educational Psychology, 88, 3-17. https://doi.org/10.1037/0022-0663.88.1.3

Gagne, E.D., Yekovich, C.W., \& Yekovich, F.R. (1993). The cognitive psychology of school learning. New York: Teachers College Press.

Girbau, D., \& Schwartz, R.G. (2007). Nonword repetition in Spanish speaking children with Specific Language Impairment (SLI). International Journal of Language \& Communication Disorders, 42(1), 5975. https://doi.org/10.1080/13682820600783210

Haebig, E., Sterling, A., \& Hoover, J. (2016). Examining the language phenotype in children with typical development, specific language impairment, and fragile X syndrome. Journal of Speech, Language, and Hearing Research, 59, 1046-1058. https://doi.org/10.1044/2016_JSLHR-L-15-0185 
Proceedings of INTCESS 2022- 9th International Conference on Education \& Education of Social Sciences 17-18 January 2022- Online Conference

Harris, T.L., \& Hodges, R.E. (1995). The literacy dictionary: The vocabulary of reading and writing. Newark, DE: International Reading Association.

Hill, E.L. (2001). Non-specific nature of specific language impairment: A review of the literature with regard to concomitant motor impairments. International Journal of Language \& Communication Disorders, 36 , 149-171. https://doi.org/10.1080/13682820010019874

Isoaho, P., Kauppila, T., \& Launonen, K. (2015). Specific language impairment (SLI) and reading development in early school years. Child Language Teaching and Therapy, 32(2), 147-157. https://doi.org/10.1177/0265659015601165

Lalioti, M., Stavrakaki, S., Manouilidou, C., \& Talli, I. (2016). Subject-verb agreement and verbal short-term memory: A perspective from Greek children with specific language impairment. First Language, 36(3), 279-294. https://doi.org/10.1177/0142723716648844

Larkin, R.F., Williams, G.J., \& Blaggan, S. (2013). Delay or Deficit? Spelling processes with Specific Language Impairment. Journal of Communication Disorders, 46, 401-412. https://doi.org/10.1016/j.jcomdis.2013.07.003

Larrivee, L.S., \& Catts, H. (1999). Early reading achievement in children with expressive phonological disorders. American Journal of Speech-Language Pathology, 8, 118-128. https://doi.org/10.1044/1058-0360.0802.118

Leonard, L.B. (2014). Children with Specific Language Impairment. London: MIT Press. https://doi.org/10.7551/mitpress/9152.001.0001

Mackie, C., \& Dockrell, J.E. (2004). The nature of written language deficits in children with SLI. Journal of Speech, Language, and Hearing Research, 47, 1469-1483. https://doi.org/10.1044/10924388(2004/109)

Mengisidou, M., Marshall, C., \& Stavrakaki S. (2020). Semantic fluency difficulties in developmental dyslexia and developmental language disorder (DLD): poor semantic structure of the lexicon or slower retrieval processes? International journal of language \& communication disorders, 55(2), 200-215. https://doi.org/10.1111/1460-6984.12512

Montgomery, J.W., Gillam, R.B., \& Evans, J.L. (2016). Sentence comprehension deficits of Specific Language Impairment: Looking back, looking ahead. Journal of Speech, Language, and Hearing Research, 59, 1491-1504. https://doi.org/10.1044/2016_JSLHR-L-15-0325

National Reading Panel (2000a). Teaching children to read: An evidence-based assessment of the scientific research literature on reading and its implications for reading instructions. Washington, DC: National Institute of Child Health and Human Development.

National Early Literacy Panel (2008). Developing early literacy: report of the National Early Literacy Panel.A scientific synthesis of early literacy development and implications for intervention. Washington, DC: National Institute for Literacy.

Passenger, T., Stuart, M., \& Terrell, C. (2000). Phonological processing and early literacy. Journal of Research in Reading, 23(1), 55-66.

Rice, M.L., Wexler, K., \& Cleave, P.L. (1995). Specific language impairment as a period of extended optional infinitive. Journal of Speech and Hearing Research, 38, 850-863. https://doi.org/10.1044/jshr.3804.850

Rodriguez, V.M.A., Santana, G.M.R., Hernández, N.V., \& Bermudez, L.C. (2016). Intervention in reading processes in pupils with Specific Language Impairment (SLI). Pricothema, 28(1), 40-46. doi: 10.7334/psicothema2015.144

Rust, J., Golombok, S., \& Trickey, G. (1993). Wechsler Objective Reading Dimensions. Sidcup, UK: Psychological Corporation.

Ryder, N., Leinonen, E., \& Schulz, J. (2008). Cognitive approach to assessing pragmatic language comprehension in children with specific language impairment. International Journal of Language and Communication Disorders, 43(4), 427-447. https://doi.org/10.1080/13682820701633207

Sengottuvel, K., \& Rao, P.K.S. (2015). Inflectional versus derivational abilities of children with specific language impairment- A panorama from sequential cognition. Annals of Neurosciences, 22(2), 87-96. https://doi.org/10.5214/ans.0972.7531.220207 
Seymour, P.H.K., Aro, M., \& Erskine, J.M. (2003). Foundation literacy acquisition in European orthographies. British Journal of Psychology, 94, 143-174. https://doi.org/10.1348/000712603321661859

Singson, M., Mahony, D., \& Mann, V. (2000). The relation between reading ability and morphological skills: Evidence from derivational suffixes. Reading and Writing: An Interdisciplinary Journal, 12, 219-252. https://doi.org/10.1023/A:1008196330239

Stanovich, K. (1986). Matthew effects in reading: Some consequences of individual differences in the acquisition of literacy. Reading Research Quarterly, 21, 360-406. https://www.jstor.org/stable/42748659

Stanovich, K, Nathan, R, \& Zolman, J. (1988). The developmental lag hypothesis in reading: Longitudinal and matched reading-level comparisons. Child Development 59, 71-86.

Stavrakaki, S. (2019). Neurodevelopmental Disorders. The case of Developmental Language Disorder. Athens: Epikentro.

St. Clair, M., Durkin, K., Conti-Ramsden, G., \& Pickles, A. (2010). Growth of reading skills in children with a history of specific language impairment: The role of autistic symptomatology and language-related abilities. British Journal of Developmental Psychology, 28, 109-31. https://doi.org/10.1348/026151009X480158

Stothard, S. E., \& Hulme, C. (1992). Reading comprehension difficulties in children: The role of language comprehension and working memory skills. Reading and Writing: An Interdisciplinary Journal, 4(3), 245-256. https://doi.org/10.1007/BF01027150

Tafa, E. (1995). Reading Ability Detection Test. Athens: Ellinika grammata.

Tager-Flusber, H. (1999). Neurodevelopmental Disorders. Cambridge, Massachusetts: MIT Press.

Talli, I., Sprenger-Charolles, L., \& Stavrakaki, S. (2016). Specific language impairment and developmental dyslexia: What are the boundaries? Data from Greek children. Research in Developmental Disabilities, 49-50, 339-353. https://doi.org/10.1016/j.ridd.2015.12.014

Tsimpli, I.M., \& Stavrakaki, S. (1999). The effects of a morphosyntactic deficit in the determiner system. The case of a Greek SLI child. Lingua, 108, 31-85. https://doi.org/10.1016/S0024-3841(98)00041-2

Van der Lely, H.K.J. (1996). Specifically language impaired and normally developing children: verbal passive vs adjectival passive sentence interpretation. Lingua, 98, 243-272. https://doi.org/10.1016/0024$3841(95) 00044-5$

Van der Lely, H.K.J., \& Ullman, M.T. (2001). Past tense morphology in specifically language impaired and normally developing children. Language and Cognitive Processes, 16, 177-217. https://doi.org/10.1080/01690960042000076

Van der Lely, H.K.J., \& Battell, J. (2003). Wh-movement in children with grammatical SLI: A test of the RDDR hypothesis. Language, 79, 153-181. https://doi.org/10.1353/lan.2003.0089

Wagner, R.K., \& Torgesen, J.K. (1987). The nature of phonological processing and its causal role in the acquisition of reading skills. Psychological Bulletin, 101, 192-212. https://doi.org/10.1037/00332909.101.2.192

Williams, G.J., Larkin, R.F., \& Blaggan, S. (2013). Written language skills in children with Specific Language Impairment. Language and Communication Disorders, 48(2), 160-171. https://doi.org/10.1111/14606984.12010 